\title{
ERJ
}

Engineering Research Journal

Faculty of Engineering

Menoufia University

\section{Understanding Overheating in Homes \\ The way in which our home is being used}

\author{
Sherif El Sayed EI Said Mohamed \\ College of Architecture \& Planning \\ Qassim Univeristy \\ El Qassim, Kingdom of Saudi Arabia \\ Sherif_donya@yahoo.com
}

\begin{abstract}
;
We have to design our houses with the goal that we can live in consolation as the temperatures rise. Cautious consideration regarding building design is basic to meet the difficulties of hotter summers, while lessening the amount of energy that we use. There seems, by all accounts, to be developing proof of overheating in homes, especially for newer houses built to fulfill all the more requesting models of energy efficiency. For some houses overheating, and related discomfort, may not be restricted to simply the hottest days of the summer.

Overheating of houses over delayed periods will have genuine consequences for the health of occupants and in extreme cases there can be a risk to life. On the other hand, with average temperatures set to increase, and more hot spells anticipated, overheating could become more common place in the future. Those most vulnerable to overheating, such as the elderly or sick, are more likely to be occupying their homes during daytime, when the heat is most intense. For this reason in particular, homes are a focus for concern on overheating.

With a warming climate, cooling will inevitably become a greater priority for people. So, passive cooling measures can greatly reduce the overheating risk for existing and new homes. Crucially, with the right investment now, passive cooling can help us avoid the alternative scenario: the potentially large energy demand and carbon emissions associated with widespread adoption of built-in and portable air conditioning in homes. So, this paper reviews overheating in homes and its causes. It stresses the high priority we should give to the adaptation and future proofing of our homes in a changing climate, and the role of passive cooling measures that can help minimize carbon emissions.
\end{abstract}

Index Terms - Overheating, Energy efficiency, Changing Climate, Passive Cooling, Carbon Emissions.

\section{INTRODUCTION}

There is no precise or accepted definition of overheating, but based on the concept of thermal comfort, BS EN 15251 suggests that there is a maximum allowable difference from comfort temperature [1]. Environmental Design, Guide A suggests that a benchmark approach be used where the summertime thermal performance of the building is measured against a temperature that should not be exceeded for a defined number of hours or percentage of the occupied hours .Therefore, When the benchmark temperature is exceeded the building is said to have 'overheated' and if this occurs for more than the designated amount of time the building is said to suffer from 'overheating' [2].

The normal, healthy human body has a core temperature range of between $36.1^{\circ} \mathrm{C}$ and $37.8^{\circ} \mathrm{C}$ and can cope with this temporarily increasing up to $38^{\circ} \mathrm{C}$ or $39^{\circ} \mathrm{C}$ without causing damage to health [3]. Regulation and maintenance of core body temperature within these parameters is managed by a part of the brain called the hypothalamus through a careful and precise balance of heat generation and loss [4]. Maintaining this balance is known as thermoregulation. The heat remaining within the body is the difference between the heat generated

Engineering Research Journal, Vol. 42, No. 2, April 2019, PP: 145-158

(C) Faculty of Engineering, Menoufia University, Egypt and the heat lost [5]. Consequently, core body temperature will rise if generation exceeds loss and will drop if loss exceeds gain [4].

The human body loses heat via a number of routes which include convection, conduction, radiation, sweating, cutaneous vasodilation, respiration and increased heart rate (See Table I) [6].

TABLE I

MECHANISMS FOR THE LOSS OF BODY HEAT [6].

\begin{tabular}{|l|l|}
\hline \multicolumn{1}{|c|}{ Route } & \multicolumn{1}{c|}{ Mechanism } \\
\hline Convection & When air or water passes over the skin \\
\hline Conduction & Contact with cooler objects on the skin \\
\hline Radiation & Electromagnetic waves in the form of infrared rays \\
\hline Sweating & Heat is released through the evaporation of sweat \\
\hline Increased heart rate & Enables blood to be brought to the skin surface \\
\hline $\begin{array}{l}\text { Cutaneous } \\
\text { vasodilation }\end{array}$ & $\begin{array}{l}\text { Increased blood flow to allow heat to escape from } \\
\text { the skin surface }\end{array}$ \\
\hline Respiration & Heat loss through exhaled breath \\
\hline
\end{tabular}

Due to differing climates across the world, people have adapted differently over thousands of years both in their physiology and in the behavioral, cultural and social practices they adopt to cope with heat [5].

Summer overheating is a 'dynamic' phenomenon and all the contributing factors and their interactions are difficult to 
simulate with steady state modelling tools. Furthermore, some factors may only manifest themselves in particular geographical areas or at a 'micro-scale', such as the 'heat island' effect, which is particular to dense urban areas. Excessive heat like this has known effects on health particularly when combined with high levels of humidity [7].

The health impacts of overheating can include an increased risk of illness from respiratory and cardiovascular disease, and the consequences of exposure to extreme warm temperatures sustained over a period are significant. In 2003 the summer heat wave across Europe is estimated to have caused the deaths of more than 35,000 people, including 2000 in the UK [8].

\section{THE CAUSES OF OVERHEATING}

Overheating in houses may be ascribed to either a solitary predominant component or various aggravated issues as Following. Unreasonable warmth gains from both inside and outside sources alongside unseemly or incapable ventilation techniques are among the key worries that must be comprehended and tended to by designers.

\section{A. Design and occupation}

\section{1) External heat gains}

Sunlight gains go through the glass and heat the indoors areas (Number 1 in Figure). These gains are consumed by interior surfaces and discharged as heat (No.2). In modern houses with double-glazed windows, this warm temperature is held well, particularly if there's a low-e coating, and can only with significant effort disseminate through the exceedingly protected building fabric (No.3). The amount of heat gain will rely upon the area of window, the house's orientation, and whether any blinds, shades or screens are utilized.

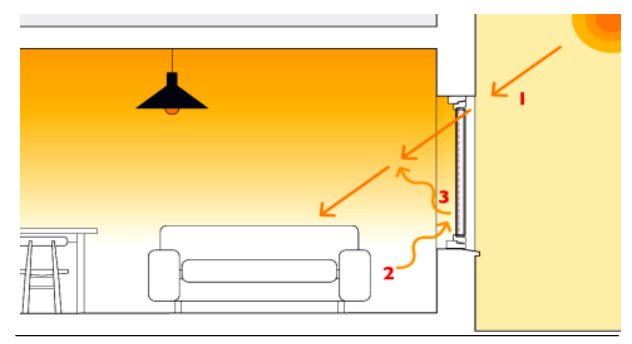

Fig. 1 External heat gain - solar [9].

\section{2) Internal heat gains}

Inner increases can range contingent upon the sort or age of house. For ongoing houses, that are steadily airtight and higher insulated, heat gain from inside sources might also have a huge impact. It might emerge from the following:

- Occupants and their activities: Occupants themselves create a variable degree of 'metabolic' heat contingent upon their activity level. Heat is likewise created by ordinary living: cooking and showering, for instance, can include noteworthy inner heat.

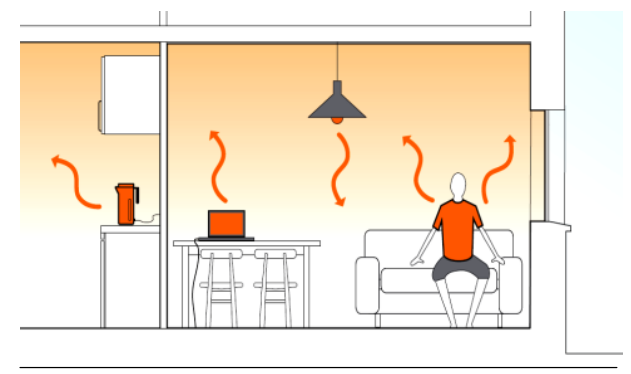

Fig. 2 Internal heat gain - Occupants [7].

- Building services: Mechanical ventilation and hot water systems can contribute significantly to heat gains. Overheating has been caused by inadequate or incorrect insulation of community heat pipes in apartment blocks.

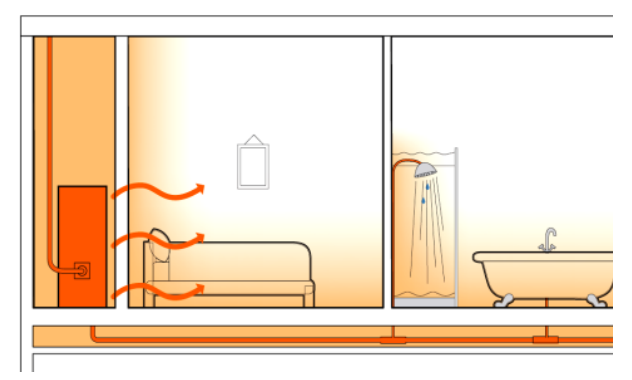

Fig. 3 Internal heat gain - services [7].

- Ventilation: Sometimes heat can build up because the ventilation design is inadequate or cannot be used properly. Simply not being able to open windows wide enough to provide purge ventilation can add to the problems and, if the night ventilation air is not sufficiently cool to remove heat from the building, the result will be a gradual build-up of heat during a hot spell.

- Lighting and appliances: Even low energy lighting can add to heat gains. Fridges, dishwashers, washing machines, TVs and computers all give off heat even in standby mode.

3) Construction type and layout

Some research is indicating that lighter weight construction may be more prone to the risk of overheating [7]. Observations also indicate that some design features such as rooms in the roof may be vulnerable to overheating in modern homes. These causes of overheating are set out in more detail in the NHBC Foundation guide NF 44 [9]. 


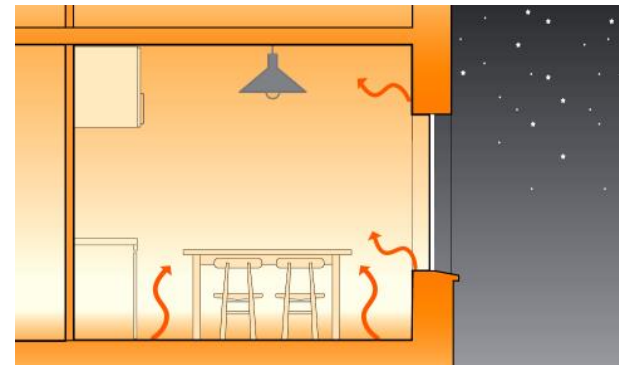

Fig. 4 External heat gain from structure [7].

\section{B. Location-related overheating}

\section{1) Site context}

The location of the building in its context have an influence on the likelihood of it overheating. A number of factors, such as the location of mechanical services close to windows and the proximity of the dwelling to noisy roads or railways lines, may compromise the occupant's ability to use the means of ventilation as intended. The conditions experienced on upper floors of homes may also be different to those on lower floors. The extent to which windows on lower floors can be used is affected by factors such as concerns for security, proximity to busy parking areas or pavements [10].

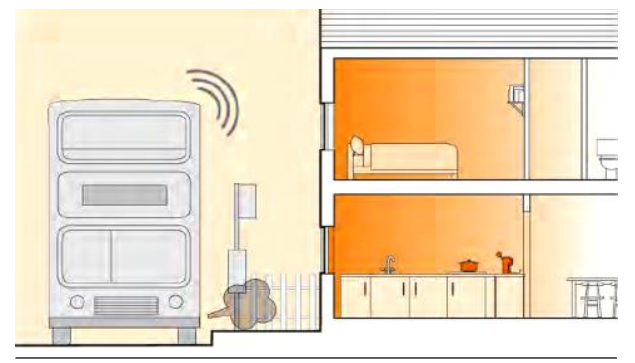

Fig. 5 Local condition may inhibit the use of windows or ventilation [10].

\section{2) Landscaping}

If the external surroundings are predominantly hard surfaces, such as pathways or car parking areas, the air available for ventilation will already be warm before it enters the home and so will have limited cooling effect.

\section{3) Urban heat island}

During the day, surrounding buildings and other hard materials absorb heat which is re-radiated into the air when the external temperature drops at night (Number 1 in Figure). Mixed-use locations often include supermarkets or food stores on lower floors which have equipment for cooling. The vents for this plant are located on the roof and are constantly running, contributing to localized heat gains, both during the day and night (No.2). As a result of heat being radiated, the night-time air temperature remains high. This means it will not be possible to ventilate the apartments with cool air at night and internal temperatures will continue to rise (No.3).

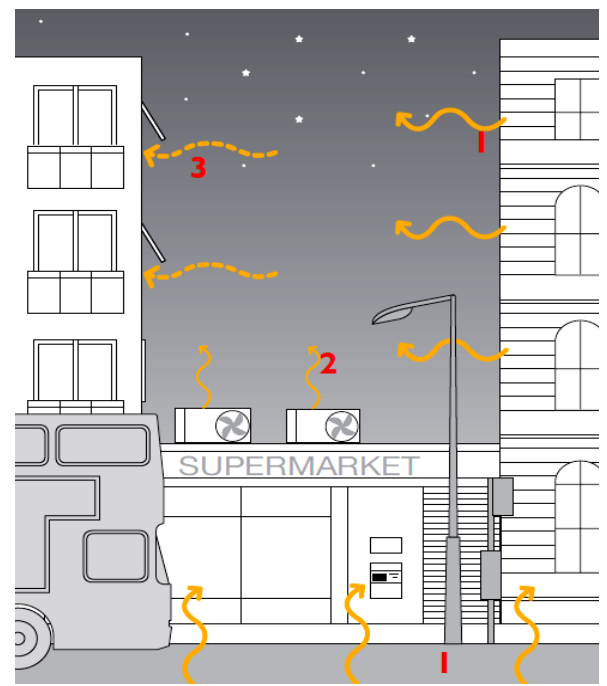

Fig. 6 Urban heat island effect [9].

The next diagram shows a typical urban heat temperature profile. At night, temperatures in dense urban city centers may be up to $4 \mathrm{oC}$ higher than those measured in rural areas. The effects can be reduced by the integration of parks, lakes and green spaces into urban areas.

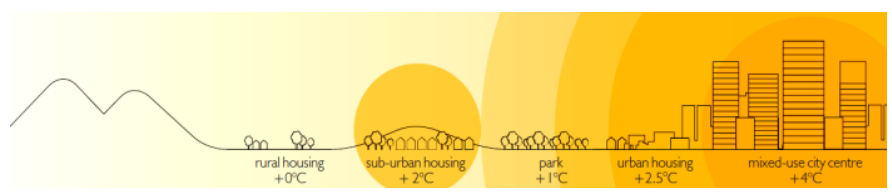

Fig. 7 A typical urban heat temperature profile [9].

\section{4) Orientation}

The orientation of a home is an important consideration, not only to take advantage of solar gains during the winter to reduce heating loads, but also to protect against unwanted solar gains that could contribute to overheating in the summer.

In one-off designs it is relatively straightforward to consider the orientation with regard to its effects on potential overheating. On larger schemes however, it is possible that one flat or house type must be repeated in different orientations. This could cause identical homes to have drastically different internal environments. An appropriate approach would be to optimize the amount of glazing and position for each orientation. 


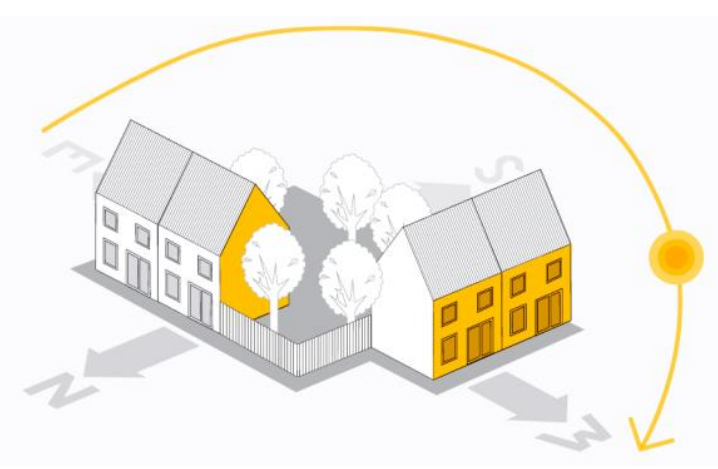

Fig. 8 West facing properties are the most likely to experience overheating [7].

\section{5) Building design}

As a result of the need to conserve energy in winter and to reduce carbon dioxide emissions, the Building Regulations have changed with the aim of improving the energy efficiency of new homes by encouraging higher standards of thermal mass, insulation and airtightness. Passive solar design strategies such as optimized orientation and south-facing windows are often incorporated to reduce the space heating load during the winter.

The warming climate and these improved thermal standards are likely to lead to overheating in homes unless appropriate measures are incorporated into the design or have the potential to be easily and effectively retrofitted. Features like recesses, overhangs and balconies may also be integrated into the building elevation as a means of providing solar shading.

Designers should consider building orientation, glazing areas and types of construction to avoid overheating. Design features and strategies, such as purge ventilation and solar shading, must also be explained to occupants to ensure that these are effective. So, we can describe conventional house and highly insulated one as follows;

- Conventional house: Heat loss through building fabric due to lower levels of insulation (as No.1 in next figure). Heat loss through leaky building fabric such as minor gaps between windows and openings in walls (No.2).
Fig. 9 Heat loss through building fabric [9].

- Highly insulated house: Increased insulation in new homes limits heat losses and gains through the building fabric (as No.1 in next figure). Improved airtightness can reduce ventilation heat losses and may also lead to the retention of unwanted heat gains inside the home (No.2). Smaller windows in bedrooms help reduce solar gains in spaces occupied at night (No.3). Use of obstructions such as optimally located trees can provide solar shading from strong and unwanted sun from the west (No.4).

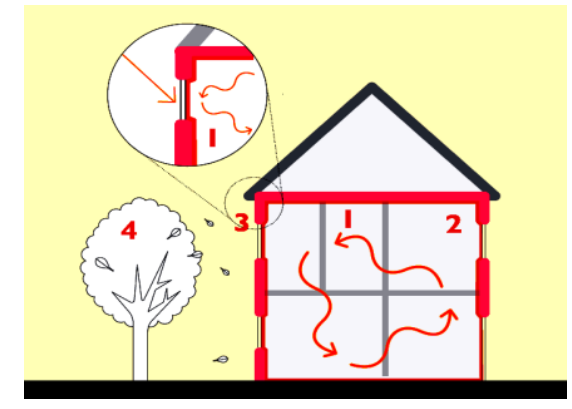

Fig. 10 highly insulated house limits heat losses and gains through the building fabric [9].

\section{6) Thermal mass}

Thermal mass refers to the ability of building materials to store and emit heat. If the design does not properly integrate thermal mass with adequate ventilation it may contribute to overheating within homes.

When the air within a space is warmed due to direct sunlight or heat gains from people and appliances, some building materials absorb heat. As the space begins to cool down at night, this heat is then re-emitted into the space.

Homes constructed to recent standards of energy efficiency are well insulated and airtight to limit heat losses in the winter. In the summer months, when the heat absorbed by building materials is re-emitted into the living space, it can contribute to uncomfortably high internal temperatures. Therefore, high thermal mass in homes can contribute to overheating unless specific measures are undertaken to limit solar gains by shading and remove heat by adequate ventilation. Thermal mass during the day and at night can describe as follows;

- Thermal mass during the day: During the day, the heavy thermal mass of the exposed external walls and floors will absorb the solar gains that enter the home. 


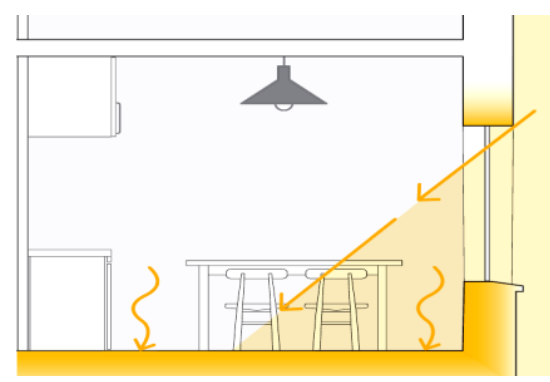

Fig. 11 Thermal mass during the day [9]

- Thermal mass at night: Heat absorbed during the day is released back into the home. In a highly insulated and airtight home where there is no provision for secure night-time ventilation, the built-up heat cannot be removed and can increase the risk of overheating.

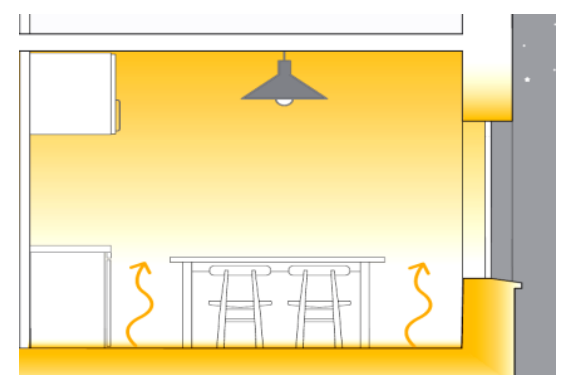

Fig. 12 Thermal mass at night [9].

\section{7) Service design in houses}

Recently, many overheating problems have been attributed to heat gain from consumer interface units (CIUs), hot water storage and distribution. Unless these components are very well insulated, they can become a source of unwanted heat gains in the summer as the demand for domestic hot water needs to be met throughout the year.

In homes where ventilation is provided by a mechanical ventilation system with heat recovery (MVHR), this heat will be distributed internally, especially if a summer bypass has not been provided. There is also the possibility that the ventilation system itself can become an unwanted source of heat. An MVHR system should be located within the insulated part of the home but its proximity to bedrooms should be limited where possible.

The distribution and storage systems for solar thermal panels need to also be well insulated as these will be circulating hot water throughout the summer months.

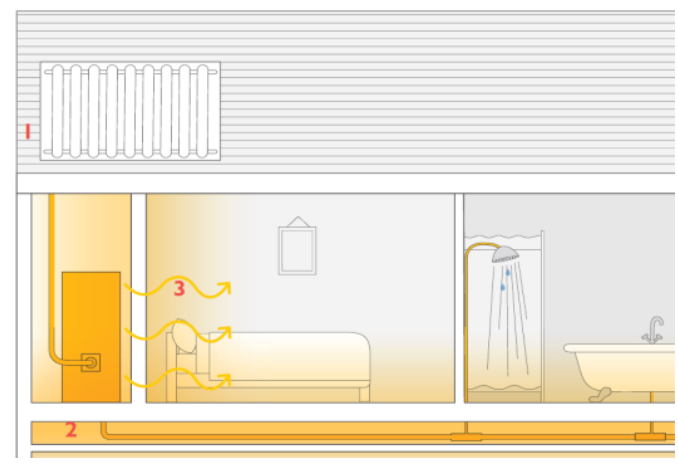

Fig. 13 Solar hot water system delivering hot water to storage tank. Even if the tank and pipework are insulated this may lead to an internal heat gain (No.1), Hot water pipework runs through the house and is continuously charged, causing an unwanted heating source (No.2), While the heat gains from both the hot water cylinder and pipework may be small, when introduced into a well-insulated, airtight home they can contribute to overheating (No.3) [9].

\section{8) Service design in apartments}

Overheating in apartments has become a greater risk as a result of single-aspect apartment designs and also where community heating pipework is routed through corridors and common spaces. In these situations, high internal temperatures are often caused by a combination of inadequate ventilation and excessive heat discharged by heating pipework.

Mechanical services installed in apartments cause heat gains in the same way as in houses but with limited scope for ventilation their impact becomes more significant. Consequently, a different strategy is required to ensure that unwanted heat is removed.

In blocks where space and water heating is provided by a community heating system, the CIU is permanently charged with hot water all year round to meet the hot water demand. This unit, particularly if not well insulated, may effectively emit heat like a radiator in the dwelling. It is often positioned in an unventilated cupboard or kitchen so heat transfers directly to the living spaces.

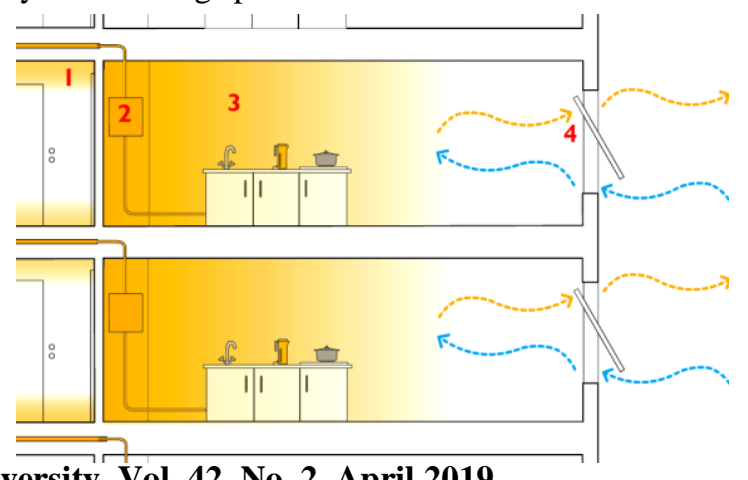


Fig. 16 Top-hung windows [9].

Fig. 14 Community heating pipework running in common areas causing internal gain within corridor (No.1), The CIU is permanently charged with hot water (No.2), If sufficient purge ventilation is not provided the internal gains from the communal areas and permanently charged CIU will lead to overheating of the apartments on warm days (No.3), It is very difficult to provide natural purge ventilation to single-aspect apartments. Sources of internal gains from services installations are likely to be located deep in the plan of the apartment and therefore furthest from the ventilation (No.4) [9].

\section{9) Restricted ventilation}

Adequate ventilation is necessary to remove heat from homes. While this may seem simple in theory, it is much harder to achieve in practice. For instance in houses, it is common to find large patio doors opening onto a garden on the ground floor. However, it is unlikely that these will be left open to provide purge ventilation, especially at night even in the safest of neighborhoods.

If purge ventilation is to be provided only by first-floor windows, it is likely that more than half of the window area would need to be fully open. Windows are often combination of fixed and opening panels and may be fitted with restrictors for safety and security reasons, further limiting the amount of ventilation that can be practically achieved. Restricted ventilation can find by the following

- Side-hung windows: When fully open, side-hung windows have the capacity to allow a high level of ventilation. However, they are particularly vulnerable to driving rain and difficult to clean.
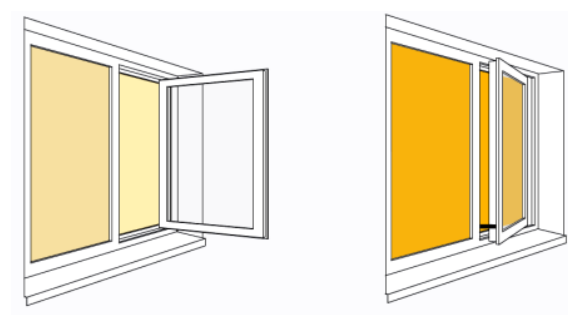

Fig. 15 Side-hung windows [9].

- Top-hung windows: Top-hung windows have the potential to allow high rates of air flow. However, due to security and safety concerns, the length of the throw of the stays is often restricted.
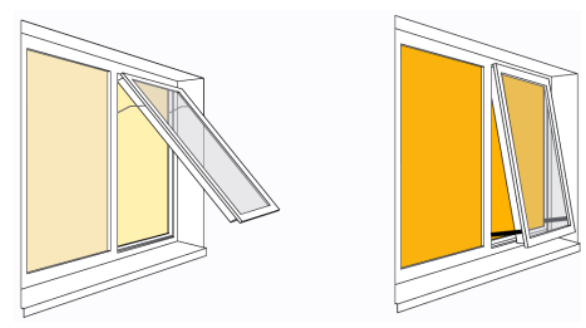

- Tilt and turn windows: If well designed, this type of window can offer versatility with regard to the types of air flow that can be provided.
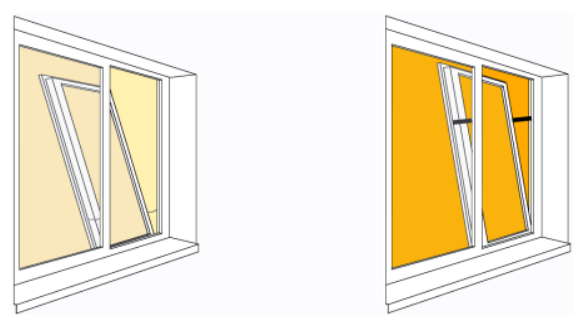

Fig. 17 Tilt and turn windows [9].

\section{0) Cumulative effects}

- Site context: External pollution, noise and excessive noise may prevent occupants from opening their windows. Surrounding hard surfaces will absorb heat and release this during the night, (as No.1 in next figure).

- External temperature: On a warm, still day when external temperatures are high, fresh air may not provide enough of a cooling effect to address overheating, (No.2).

- Solar gains: Double-glazed windows with a low-e coating prevent heat from escaping. Houses with unshaded west-facing glass suffer from higher levels of solar gain in the warmer part of the day, (No.3).

- Internal gains: Electrical appliances, occupant activities such as cooking, and building services, e.g. boiler and hot water storage, all have the potential to radiate heat that may contribute significantly to the increasing internal temperatures, (No.4).

- Building design: Modern homes have increased levels of insulation and airtightness, resulting in more heat being retained within the homes. So, any built-up heat in the homes will have to be actively removed, (No.5).

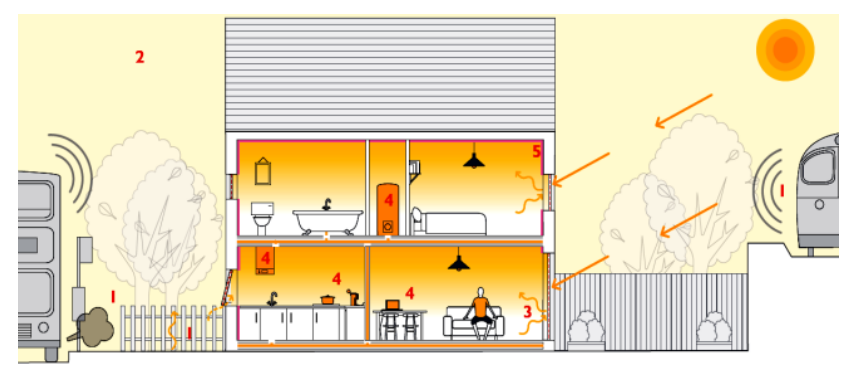


Fig. 18 Illustration some of the causes and effects of overheating in homes [9].

\section{TACKLING OVERHEATING}

Overheating is caused by a variety of effects. Tackling it requires an approach that can be implemented on a large scale, neighborhood scale and at the scale of the individual home, including advice to owners. For new urban or suburban development, overheating should be a key consideration at planning application stage.

\section{A. Planning considerations}

\section{1) The large scale - conurbation}

Because cities are already showing evidence of overheating through the urban heat island effect and are likely to have to endure the highest temperatures in the future, consideration has often been given to strategies to minimize heat accumulation in the urban environment [11]. Possible measures include the inclusion or preservation of larger scale greenspace areas (greens, woodland and parks) and major bluespace features (lakes and urban canals) and the integration of these measures within the city's masterplan.

Such measures have been applied in practice on projects like the internationally-acclaimed Chicago Wilderness project [12] where urban forests and blue-space now occupy more than 100,000 hectares within the city. This is an important demonstration of a way of minimizing the urban heat island effect, and methodologies are now emerging to help in decision making on climate change adaptation at the conurbation level.

The orientation and design of an existing conurbation's built infrastructure may be difficult to adapt. However with new urban areas there will be the opportunity, for example, to exploit shading and orientation to minimize solar gain and to achieve passive ventilation through the management of air flow.
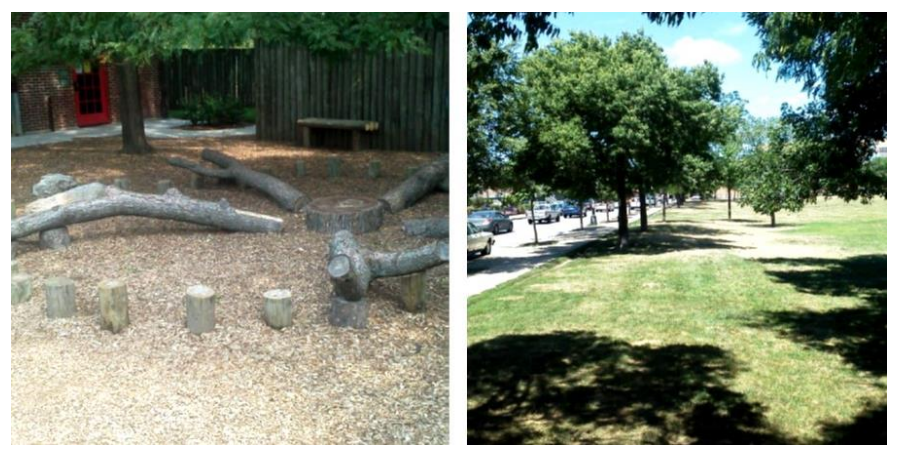

Fig. 19 There Two municipal parks in Chicago Wilderness: Indian Boundary Park (left) and Harrison Park (right) [14].
The orientation and design of an existing conurbation's built infrastructure may be difficult to adapt. However with new urban areas there will be the opportunity, for example, to exploit shading and orientation to minimize solar gain and to achieve passive ventilation through the management of air flow.

- Neighborhood scale: At the neighborhood scale, the overall aim is to provide cool and attractive outdoor areas. The focus is on measures that have a direct interaction with nearby buildings and achieve a cooling influence on internal areas. There are essentially three categories of measures [13]:

Evapotranspirative cooling: Trees in leaf not only provide shade, but cool the air around them as their leaves transpire water. Their potential for reducing temperature is dramatic (Figure 20). Significant cooling effects can also be achieved with green roofs and green walls (planted roofs and walls).

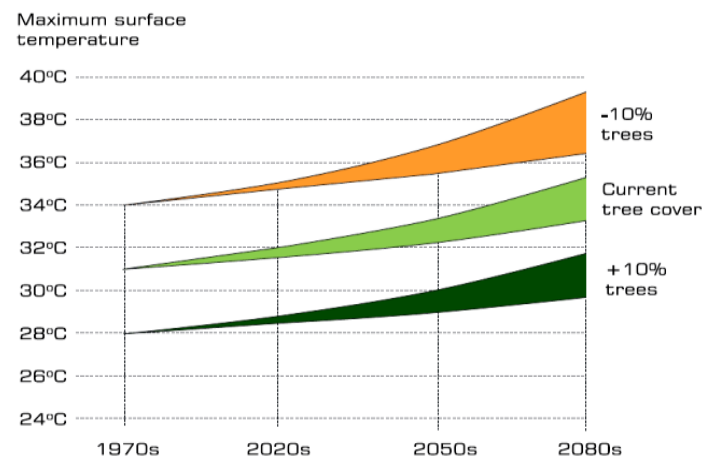

Fig. 20 Additional tree planting can protect cities from extremes of heat. This graph is based on modelling work by ASSCUE [14]. Upper and lower edge of color band=high and low greenhouse gas emissions scenarios respectively.

Local water features: Using ponds, swales, flood balancing lakes, and fountains.

Cool infrastructure surfaces: Here the aim is to reflect heat rather than absorb it. Measures include reflective pavings, parking area surfaces, reflective roofs and facades.

In-depth studies have demonstrated the challenge [15] and potential [16] of achieving change in existing suburbs.

\section{2) Design considerations}

There are many features that designers can use to minimize overheating in homes. The merits and limitations of these are discussed in detail elsewhere [9]. Approaches include:

- Thermal mass: Utilizing the benefits of additional thermal mass in the design, for example concrete floors. These measures must be used in conjunction with secure and cool night-time purge ventilation. 
- Solar shading and shutters: Many external shading devices and shutters are available (including automated systems that sense risk of overheating). These can be used to good effect to reduce the heating effect of the sun.

- Cooling ventilation strategies: Enabling a home to have an effective passive cooling strategy (including purge ventilation) has many benefits, particularly if it can utilize cross ventilation through the home. However, correct operation does rely on occupants understanding how it should be used.

- Heat reflective finishes: Light external finishes on homes and reflective roofs or green roofs play a part in keeping temperatures down.

- Planting: Plants can provide valuable shade and cooling effects for individual homes. Deciduous trees, vines and climbers have been used very effectively to reduce overheating risk and can also contribute interest and biodiversity.

\section{FACTORS THAT REDUCE THE RISK OF OVERHEATING}

Careful attention to building design is essential to meet the challenges of hot summers and winters, while reducing the amount of energy that we use. So, we need to design our homes so that people can live in comfort as the temperatures rise.

\section{A. Purge ventilation}

One of the most effective ways of addressing the risk of overheating in homes is to have a well thought out strategy for purge ventilation. This can be achieved by providing means for cross-ventilation that is, circulating large amounts of air throughout the home. Where mechanical ventilation is used, occupants should be able to open windows adequately and in a secure manner, even if for short periods of time [10].

Even homes with MVHR systems should allow for opening windows for the removal of heat. In these homes, background ventilation, in both summer and winter, is provided by the mechanical ventilation system.

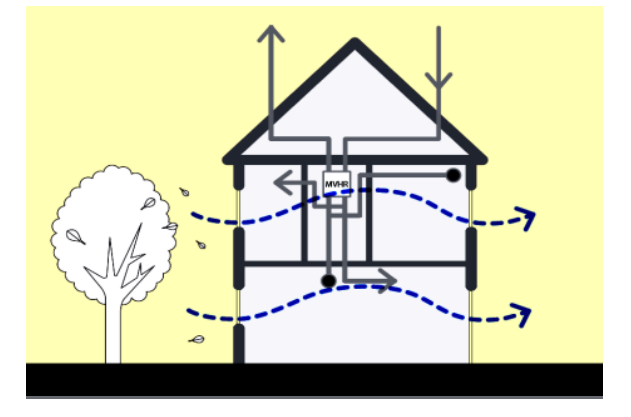

Fig. 21 Purge ventilation in home with MVHR systems [10].

\section{B. Thermal mass}

The thermal mass of building materials, or their ability to store heat, can be used to control overheating when used in conjunction with adequate ventilation.

Materials with high thermal mass will absorb sunlight and internal gains and store it during the day. This heat is released into the home at night, effectively 'shifting' the period of high internal temperature to when the outside air is cooler; this effect is called 'thermal lag'.
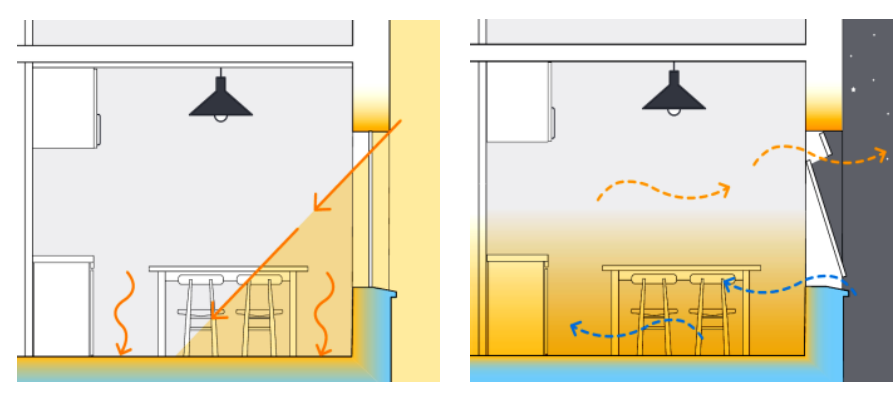

Fig. 22 During the day, the thermally heavy materials are absorbing the solar gains that enter the dwelling through windows. Then, they will be perceived as offering a cooling effect. At night, for thermal mass to be effective there must be some way of cooling down the structure at night in a secure manner [9].

In order to achieve this effect, materials with high mass must be used where they are exposed to the internal environment but ideally not to direct sunlight. Internal finishes such as carpets and plasterboard can reduce the effectiveness of thermal mass and their impact must be considered in the early stages of design.

The materials that will store heat will need to be sufficiently cooled to be effective during prolonged periods of hot weather. One way of achieving this is by providing secure night-time ventilation, also called 'night purge' ventilation, to allow the thermally heavy materials to cool down so that they may absorb heat as temperatures rise the following day.

\section{Window design}

Windows commonly incorporate trickle ventilators within their frames to provide background ventilation to maintain indoor air quality. In the summer, in well-insulated and airtight homes, a higher rate of ventilation is desirable for air circulation and regulating internal temperatures preferably at all times. Security needs to be taken into account and may be implemented by fitting restrictors in the window frames, ventilation panels or high-level windows, which can be left 
open when the occupants are not present or at night. Traditional sash windows, which can be left open at the top securely, are a good example of how secure ventilation has been achieved in the past.

In addition to this, it should be possible to open windows to their full capacity for short durations of time in order to get maximum air flow through homes.

The design of windows should also take into account regulating the amount of solar gains within homes. The glass in windows is generally specified to maximize daylight into spaces while reducing heat loss in the winter by the use of lowe coatings. However, window design should also consider the incorporation of solar shading. Inward and outward opening windows will also have implications for the choice of shading devices.

- Secure ventilation: Both of these windows can be used in single-aspect homes when high- and low-level openings will help generate a stack effect.

Traditional sash windows where the upper and lower panes can be moved to an opened position. b) Windows with a separate top vent that can be left open along with or independent of the main window. Secure ventilation may be achieved by a louvered panel alongside window [9].

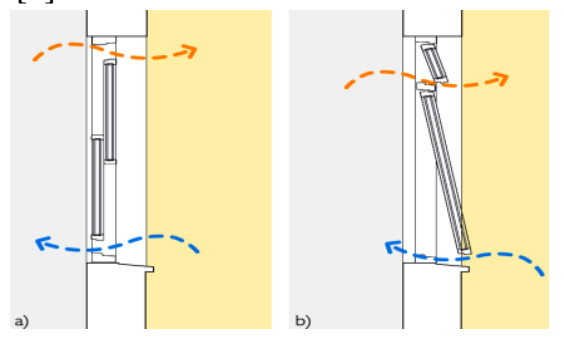

Fig. 23 Secure ventilation [9].

- Ventilation \& solar shading: Solar shading devices like blinds may be: c) fixed to the outside of windows which would limit the extent to which sunlight will come into the room; or d) integral to the glazed unit and restrict sunlight before it enters the home.

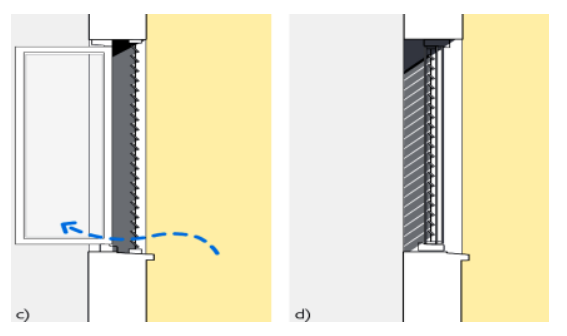

Fig. 24 Ventilation \& solar shading [9].

\section{Solar shading devices}

Windows in homes can be used as curtains to retain heat in the winter. Curtains can also provide some protection from solar gains in the summer, but to prevent overheating, it is more efficient to provide shading that cuts sunlight before it enters the building. In an ideal situation the choice of the shading device that is used is determined by the orientation of the opening where it is installed [17]

- High-level sun: South-facing windows need to be protected from high-level sun. This may be done either by projections of the building form itself or balconies or overhanging eaves.
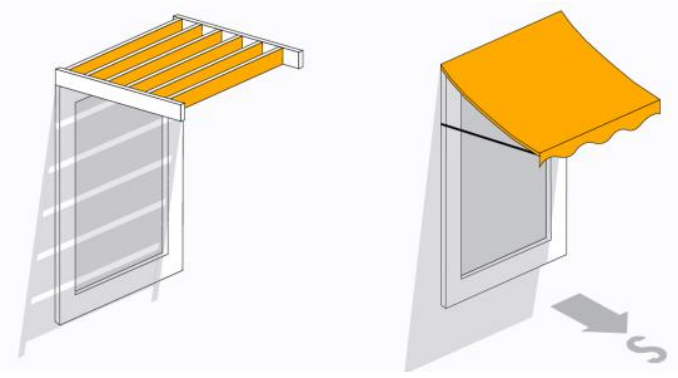

Fig. 25 Left: brise-soleil - Right: awning [9]. Generally these devices block the sun, with a limited impact on views out.

- Low-level sun: Vertical shading devices are most effective for windows facing the east or west, which are vulnerable to low-level sun. These often reduce the external views and, to a lesser extent, daylighting.
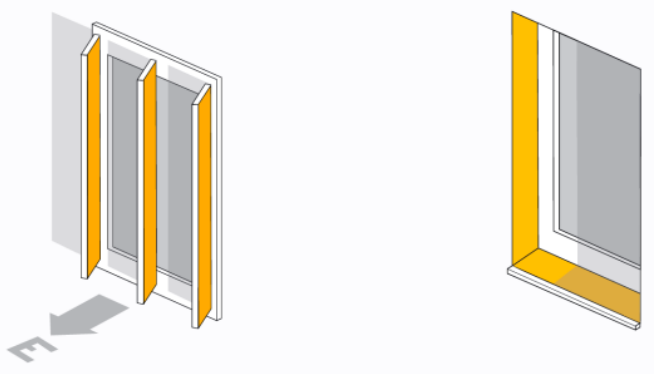

Fig. 26 Left: vertical louvres - Right: deep window reveals [9].

- General shading: Shading features which cover the windows are the most effective for both high- and low-level sun, but they may completely restrict views to the outside and daylighting.

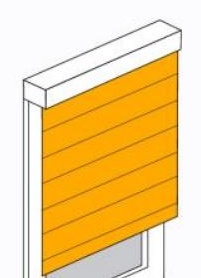


Fig. 27 Left: external blinds - Right: external shutters [9].

\section{E. Shading devices}

A balance between useful and unwanted solar gains can often be achieved with shading with carefully-thought-out shading. While internal blinds can offer relief from glare due to direct sunlight, they have a limited impact in protecting against solar gains. The homes should be shaded externally as far as possible. This may not always be an architectural statement consisting of external louvres, overhangs or screens, though these treatments are appropriate and highly effective.

In Hot climates, porches or patio doors are frequently shaded by a pergola with deciduous planting. Vines can provide dense flat-leaved shading in the summer but during the winter, the minimal branch structure allows winter sun to penetrate the living space. Manual external shutters are also extremely effective devices and offer shade along with secure ventilation, provided that the window is designed to open inwards.

Hot climates have inward opening windows and relying on the shutter to provide weather protection provides a readymade solution that could easily be adopted within our traditional building apertures [18].
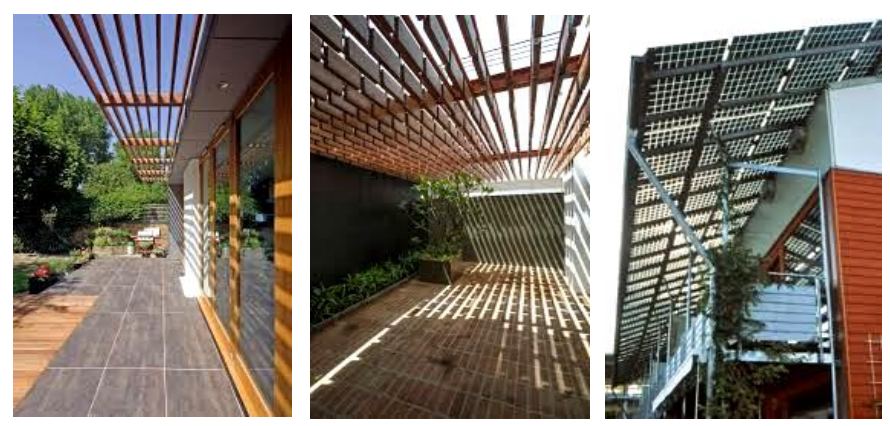

Fig. 28 There are a variety of approaches that may be taken when providing solar shading to a home. These include creating an overhang by the building form along with retractable awnings and external louvres [18].

\section{ASSESSMENT OF OVERHEATING}

\section{A. Standard Assessment Procedure (SAP)}

SAP is the Universal approved tool that is used to demonstrate compliance with the Building Regulations with regard to the conservation of fuel and power for space and water heating, fixed lighting and ventilation in a home. It also checks for excessive solar gains during the summer to minimize demand for mechanical cooling.

SAP makes monthly average energy demand assessments and has limited ability to account for the complex interactions that occur in the home.

As an alternative to using SAP, 'dynamic' modelling can be carried out to assess various design strategies. Dynamic modelling evaluates the performance of a dwelling throughout the year and allows the designer to undertake a more detailed assessment of the risk of overheating [19].

\section{1) SAP Tools:}

Commercial tools are available which implement the SAP methodology. The BRE website lists SAP tools which are approved for the purpose of demonstrating Building Regulations compliance.

2) SAP Overheating Calculation:

The SAP calculation takes account of several factors.

- Solar gain in the dwelling; depending on:

- Glazing orientation,

- Solar shading of glazing,

- Glazing solar transmission.

- Natural ventilation via openable windows; for which the user inputs

- Type of ventilation opening - trickle vents, slightly open windows, windows open half the time or windows fully open,

- Type of dwelling - single story or two or more stores, Whether cross ventilation is possible.

The calculation then takes a single value, from a table, for the effective 'air change rate'.

- A design air change ventilation rate for mechanical ventilation, which can be specified by the user.

- The construction thermal capacity (the thermal mass).

- Weather inputs for the chosen location, Mean monthly values for June, July, and August of:

- Monthly external temperature;

- Wind speed; and

- Solar radiation.

- Internal heat gains and profiles for occupancy, equipment and lighting; depend on the floor area and cannot be adjusted by the user.

\section{B. CIBSE Design Guidance}

The Chartered Institution of Building Services Engineers (CIBSE) has produced guidance on calculating overheating risk.

Unlike SAP, these standards relate to hourly temperatures in bedrooms and living rooms for the period during which the 
home is occupied, so designers need to use dynamic thermal simulation to calculate them.

\section{1) CIBSE Guide A Environmental Design: 2006 Edition:}

In the previous 2006 edition of CIBSE Guide A Environmental Design, overheating is deemed to occur if the living room temperature exceeds $28^{\circ} \mathrm{C}$ for more than $1 \%$ of the time the room is in use [20].

High night-time temperatures can lead to disrupted sleep and impair a person's ability to recover from heat stress during the day, so a lower peak threshold temperature of $26^{\circ} \mathrm{C}$ is used for bedrooms. The Guide suggests that sleep quality may be impaired once indoor temperatures exceed $24^{\circ} \mathrm{C}$.

TABLE 2

TEMPERATURE THRESHOLDS FOR THE DESIGN OF BUILDINGS [19].

\begin{tabular}{|c|c|c|}
\hline \multicolumn{1}{|c|}{ Building type } & Peak temperature $\left({ }^{\circ} \mathrm{C}\right)$ & Overheating criterion \\
\hline Homes - living areas & $28^{\circ} \mathrm{C}$ & $\begin{array}{c}1 \% \text { annual occupied hours } \\
\text { over peak temperature }\end{array}$ \\
\hline Homes - bedrooms & $26^{\circ} \mathrm{C}$ & verat
\end{tabular}

\section{2) CIBSE Guide A Environmental Design: 2015 Edition:}

Guide A adopts the Adaptive Thermal Comfort approach, which states that occupants are 'comfortable' with higher room temperatures during periods of prolonged warm weather [21]

\section{Dynamic Thermal Simulation Models}

Dynamic thermal simulation models are powerful software tools, which model the energy interactions and internal environmental conditions in a building on an hour-by-hour basis.

Developed primarily for use in designing commercial buildings, they have many applications including sizing heating and air conditioning plants, evaluating energy performance and checking Building Regulations compliance, as well as predicting overheating risk.

They can model more complex buildings and features, for example, different heating, ventilation and cooling technologies, external shading devices and newer technologies such as Phase Change Materials (PCM).

\section{1) A significant amount of data is input into the models:}

- Building geometry, location and orientation;

- Detailed construction information about how the fabric is built up and the thermal properties of each of the materials used;

- Internal heat gains from people, lighting and equipment, and the daily patterns that these will follow;

- Ventilation information; and

- Hourly weather data.

The model outputs include energy consumed for heating, ventilation and cooling, and the internal temperature in each zone modelled. Most commercial tools have built-in functionality to calculate overheating risk using standard methodologies and criteria.

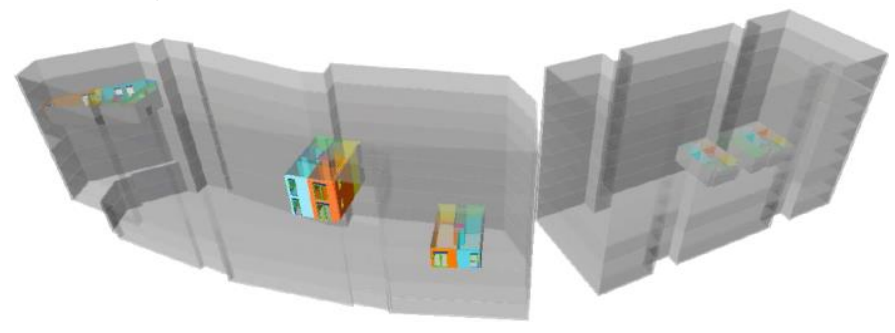

Fig. 29 Example model of units in an apartment block [19].

D. Computational Fluid Dynamics (CFD)

Dynamic thermal simulation models assume that the air temperature in each zone is uniform. CFD models can be used to model more complex air movement and temperature patterns but entail significant computational cost [22].

\section{E. Urban and Neighbourhood Scale Models}

Modelling for microclimatic effects is highly complex and usually done only for research purposes. These models consider local factors such as detailed urban geometry, street layout and building heights, vegetation and moisture in the form of trees, parks and rivers, types of urban surfaces and materials, and anthropogenic heat emissions.

\section{F. Passive House Planning Package (PHPP)}

Designers of Passive house buildings use the Passive House Planning Package, a complex spreadsheet developed by the Passive house Institute in Germany, to calculate overheating risk. PHPP uses a monthly calculation, similar to SAP, to calculate the frequency of overheating. The key difference is that PHPP is able to use actual data for internal heat gains from occupancy, lighting and equipment [23].

\section{G. Computational Passive Design Assistant}

This is a free software tool, developed by ARUP that demonstrates the principles of passive thermal design [24].

\section{CASE STUdIES}

Many of the case studies presented here reveal that modern homes can overheat, even if there are no obvious causes. High internal temperatures may be associated with location and orientation, fundamental oversights in design, or the way in which the home is being used.

\section{A. Case study 1-Test homes:}

Four test houses were built by the BRE in the early 1990s. Two were built to comply with the current standards and the other two to meet the more stringent Swedish building fabric standards. Soon after completion, the houses built to meet the Swedish standards were experiencing high internal temperatures [7]. 
A study was then undertaken to assess the potential for passive cooling measures to limit the extent of overheating. The following measures were considered:

- Various window opening strategies, including singlesided ventilation and cross-ventilation,

- Thermostatically controlled mechanical ventilation and 24-hour ventilation, and

- The use of solar blinds on unshaded elevations.

The investigation concluded that to achieve effective cooling of the whole house cross-ventilation was required on both floors. One suggestion from the project was that houses might need different ventilation systems for the ground and first floors, recognizing the security limitation for natural ventilation at night time on the ground floor. The study also concluded that external solar blinds were very effective at limiting solar gains within the homes, helping reduce daytime and night-time temperatures.
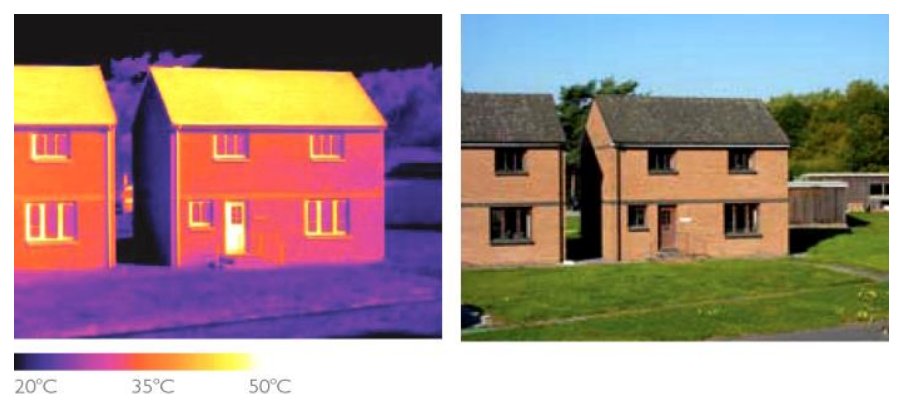

Fig. 30 Images of the houses built to the Swedish building fabric standards. After completion, high temperatures were observed during the day as a result of simulated internal gains and solar gains [7].

\section{B. Case study 2-Varying degrees of shading:}

An environmental health survey was carried out in this new development located in a dense urban area. The flats were built to a high standard of fabric insulation and airtightness. A large proportion of these were single aspect and located near to a busy railway line. The ventilation was provided by a mechanical ventilation system that incorporated heat recovery for winter operation. Space and water heating was provided by a community heating system. Inadvertently, these features led to an overheating problem.

As a result of unshaded facades, a high level of occupancy and gains from the hot water distribution pipework, heat was building up during the day which could not be removed.

In order to address the problem, the developer improved insulation to the hot water distribution pipework and installed fans in the common areas to remove heat emitted from the community heating system. Although these measures will help to alleviate uncomfortable temperatures, the additional fans will increase the energy consumption of development [9].

the
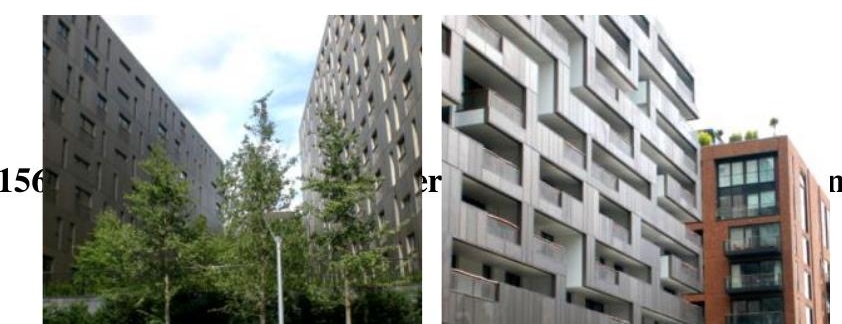

Fig. 31 One part of the housing scheme (left) has no solar shading and some apartments overlook the busy railway. In contrast, the west-facing façade (right,) has deep set balconies protecting the glazing from solar gains [9].

\section{Case study 3-Effect of the urban heat island:}

A number of factors contribute towards overheating of this one-bedroom flat located on the ground floor of an eight story development facing a major road. The single-aspect flat has a south-west facing facade incorporating large areas of unshaded glazing. It is ventilated via trickle vents in window frames and extract fans in the bathroom and kitchen.

The outward-opening side-hung windows have been fitted with restrictors.

The flat experiences significant solar gains during the day due to its south-west orientation. Concerns regarding security, pollution and noise make it difficult for windows to be left open for extended periods during the day or night. Effective nighttime purge ventilation is therefore not possible and only the trickle vents are used. In addition to this, the surfaces adjacent to the apartment, the hard paved areas and brickwork, absorb heat from the sun during the day and radiate it back at night, further limiting the effectiveness of night-time ventilation [25].

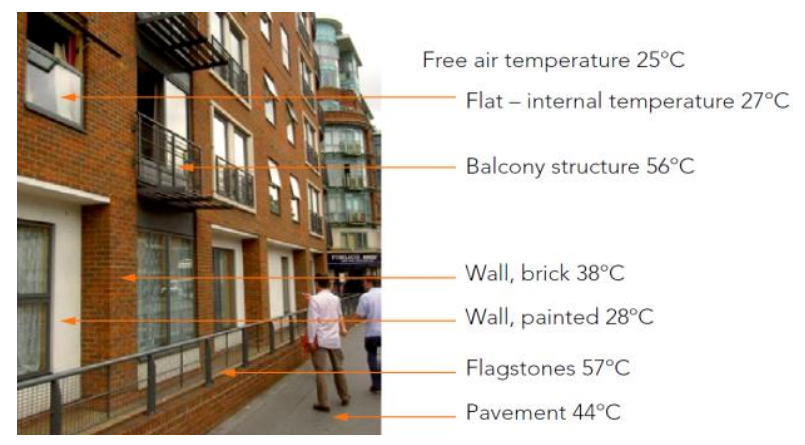

Fig. 32 Thermographic images show the high temperatures of the external surfaces of the apartment building and its immediate surroundings because of their direct exposure to the sun. Air introduced into the flat by opening windows will therefore be significantly warm [25].

The combination of high solar gains and the urban heat island effect will cause this flat to be continuously exposed to high temperatures. The lack of effective day or night-time ventilation will make it difficult for the high internal temperatures to be reduced easily and these will be compounded over time. 


\section{Case study 4-Excessive heat gain from the CIU:}

Overheating was reported in a number of apartments in an eleven-story mixed-use urban development that overlooks a busy railway line.

An MVHR system provides background ventilation and large side-hung windows are located on the unshaded eastfacing facade for purge ventilation [7].

A community heating system meets the space heating and domestic hot water demand, the distribution pipework for which runs through common circulation areas. Although solar gains to the apartment are high, these take place in the morning when the sun is not at its warmest and were not thought to be the main cause of overheating.

During the night, internal temperatures were high in the bedroom and living room, even with moderate external temperatures.

A significant length of pipework to the CIU for the community heating system was poorly insulated, effectively making these a permanent heat source. Pipework located directly alongside the MVHR unit was pre-heating the fresh air supplied to the apartments.

The MVHR unit did not incorporate a summer bypass setting, due to which the supply air was always being preheated. Even in 'boost mode' the rate of mechanical ventilation was not high enough to help reduce internal temperatures [9].
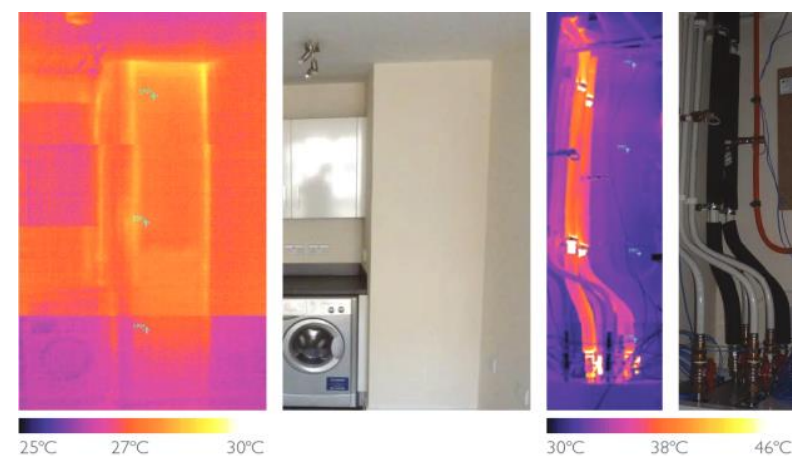

Fig. 33 Infrared images of the airing cupboard in the kitchen show the extent of the heat that is constantly being emitted as a result of the poorly insulated pipework from the heating system that was running alongside the MVHR ductwork [9].

The windows could not be opened at night due to noise and security concerns, further limiting the potential for ventilation.

The ventilation strategy was inadequate for the apartments and even the relatively small heat gains from the CIU made a significant contribution towards high internal temperatures and occupant discomfort.

\section{E. Case study 5-Creation of a 'hot spot':}

A program of post-occupancy testing was undertaken in this recently built energy efficient house. In addition to a highly insulated and airtight building fabric, the energy strategy included an efficient mechanical ventilation system with heat recovery (MVHR).

The summer ventilation strategy used a passive solar stack located in the middle of the house through which warm air would rise and be expelled via an automatically operated vent. All the windows were designed to be openable and controlled by the occupants to allow them to cross-ventilate the house and facilitate stack ventilation to purge the house in warm weather.

The passive stack ventilation was found to be effective; however one bedroom on the first floor was reported to be uncomfortably warm all of the time. This bedroom was immediately adjacent to a room housing the hot water cylinder and the MVHR system, which was identified as a source of heat - a 'hot spot'. This problem was reduced by improving the insulation to the pipework of the hot water distribution system.

Monitoring of the use of windows revealed that only 4 of the 25 openable windows were regularly used. The summary report concluded that more thought was needed for the positioning of windows within the layout for effective crossventilation [9].

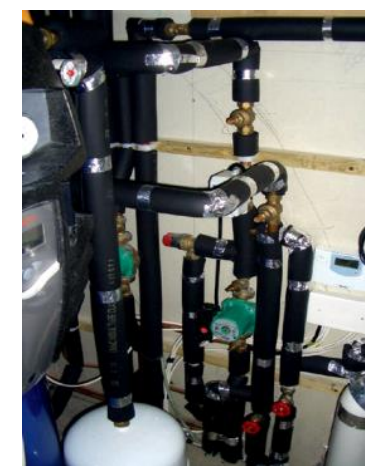

Fig. 34 A 'hot spot' was created in the airing cupboard by the MVHR unit and the pipework around the hot water cylinder. Additional insulation was later added to the pipework, which helped address the problem [9]. VII. CONCLUSIONS

In a changing climate the risk of overheating in new homes is likely to increase. 
An overheating problem may be caused by a single design or installation fault but it is just as likely to be caused by a combination of seemingly harmless factors.

Design measures to reduce overheating need to be able to be put into practice successfully, especially for window opening and cross-ventilation.

Designers need to consider external factors - the site and its surroundings - as well as the home itself.

Design guidance must consider inlet location for ventilation systems since sourcing air from south-west façades will exacerbate overheating, regardless of the ability to undertake effective night-time ventilation.

Good design for 'purge' ventilation will go a long way to help reduce overheating.

Services, especially those that are fully charged with hot water all year round, need to be designed and installed with consideration for the potential to cause overheating.

Home users need to be made aware of the ways in which they can regulate their internal environment to address any possible overheating, while designers need to ensure that all features that would aid this are easy to understand and operate.

The means of rejecting heat, without recourse to mechanical cooling, are very limited. To effectively use ventilation requires secure, acoustically treated openings, which are able to draw air from a pollution-free location. Night-time ventilation needs to be automated to minimize the potential for over cooling. Systems need to be developed that can achieve this in existing dwellings, and this needs to become a requirement for new urban dwellings.

A practical assessment of the effectiveness of inclusion of thermal mass and night-time ventilation in new dwellings must be undertaken. Much of the modelling suggests that this may be very effective, but models often make assumptions of perfect control, and the sensitivity of the effectiveness of thermal mass to the night-time ventilation needs to be determined in order to deliver robust designs.

Night-time temperatures are important because higher night-time temperatures are thought to increase the risk to health due to the inability to recover from daytime heat stress and the interruption to sleep.

The prototype houses built to zero carbon standards are suffering from overheating - which shows overheating may also become an issue where cross ventilation is achievable in lightweight, airtight houses with little or no solar shading.

\section{RECOMMENDATIONS}

Comprehensive studies are required on indoor heat and health. Further research is also required into the types of housing inhabited by those who have suffered heat-related illness.

More study of the relationship between external and indoor temperature is required. Study of the health of occupants in relation to exposure to excess heat experienced when indoors is needed to inform the identification of thresholds for internal temperatures.

There is a pressing need to develop a universally accepted definition of overheating in dwellings for use by planners, designers, builders and authorities which is vital for dealing with overheating.

Further research is needed on how thresholds should take account of a changing outdoor climate and the effect of minimum night-time temperatures and diurnal variation.

The effectiveness of traditional means of achieving comfortable internal environments (including thermal mass, shading, openable windows) for modern buildings also needs to be investigated. Work is needed to develop, trial and introduce systems which are capable of rejecting heat from existing dwellings, and to determine whether such systems should become a requirement for new urban dwellings.

Robust solutions must be sought for minimization of heat gains in all future designs, and work carried out on potential adaptation of such solutions for application to the existing stock. Evidence based, clear and authoritative design guidance is required for practitioners on the required techniques including use of thermal mass, shading and effective inlet location for ventilation systems. Tools are required with which to assess the practical effectiveness of thermal mass and nighttime ventilation in new dwellings.

Building energy models, including SAP, need to be applied to take account of overheating using data from building monitoring and case studies. Factors that must be considered in any modelling tool include: effectiveness of night-time ventilation and thermal mass, the influence of real building micro environments and the boundary layers around building façades, realistic heat gains and the influence of occupants. However, it is also important that modelling tools are affordable, not overly complex to use and widely applicable.

Effective means of educating occupants (and their support network in the case of the vulnerable) are required. Behavior adaptation and the effective use of buildings and their systems are required in order to minimize the effects of overheating.

\section{REFERENCES}

[1] BSI, "Indoor environmental input parameters for design and assessment of energy performance of buildings addressing indoor air quality, thermal environment, lighting and acoustics," BS EN 15251:2007. London, BSI, 2007.

[2] Chartered Institution of Building Services Engineers (CIBSE). "Environmental design," Guide A. London, CIBSE, 2006.

[3] Kovats S and Hajat S., "Heat stress and public health: A critical review," Annual Review of Public Health, 2008, 29 (9)1-9.15.

[4] World Health Organization (WHO) (Regional Office for Europe), "Heat health action plans," Copenhagen, WHO, 2008.

[5] WHO (Regional Office for Europe), "Heat-waves; risks and responses. Health and global environmental change," Series 2, 2004, www. euro.who.int/_data/assets/ pdf_file/0008/96965/E82629.pdf (accessed 17 September 2012).

[6] Havenith G., "Interaction of clothing and thermoregulation. Exogenous Dermatology," 2002 (1) 221-268. 
[7] NHBC Foundation, "Overheating in new homes - An introduction for planners, designers and property owners," AECOM, (2012).

[8] Johnson et al., "The impact of the 2003 heat wave on daily mortality in England and Wales and the use of rapid weekly mortality estimates," Euro surveillance 10 (7-9) p168-171, (2005).

[9] Richards Partington, "Overheating-Where to start: An introduction for house builders and designers, "NHBC Foundation, ISBN 978-1-84806279-5, July (2012).

[10] Zero Carbon Hub, "Overheating and Ventilation in homes, New projects.", Layden House, London, (2016), www.zerocarbonhub.org

[11] http://www.rospa.com/homesafety/policy/childsafety.aspx

[12] Shaw, Colley Connell, "Climate change adaptation by design - a guide for sustainable communities," TCPA (2007). www.tcpa.org.uk/data/files/bd_cca.pdf

[13] SNACC Final Report, "Suburban neighborhood adaptation for a changing climate," (2012). http://snacc.files.wordpress.com/2012/10/snacc_report.pdf

[14] Leslie A. Brandt et al., "Chicago wilderness region urban forest vulnerability assessment and synthesis," Forest Service Northern Research Station, General Technical Report NRS-168 (April 2017). www.chicagowilderness.org/

[15] www.myerscough.ac.uk/downloads/pdfs/Subjects/Arboriculture $\% 20 \% 20$ NYTOG/NWTOG11/Ennos\%20$\% 20$ Trees\%20and\%20Climate\%20Change.pdf

[16] Williams et al., "The conditions for, and challenges of, adapting England' s suburbs for climate change," Building and Environment, 55 p131-140 (2012).

[17] CIBSE, "Design for improved solar shading control." Technical memorandum TM 37, London, CIBSE, (2006).

[18] Little fair P., "Solar shading of buildings." BR 364. Bracknell, IHS BRE Press, (1999).

[19] Inkling LLP, CIBSE, UCL and ARCC, "Assessing Overheating Risk." LEAFLETS for Housing Associations and Local Authorities, (2011).

[20] Chartered Institution of Building Services Engineers (CIBSE), "Environmental design, Guide A." London, CIBSE, 2006.

[21] Chartered Institution of Building Services Engineers (CIBSE), "Environmental design, Guide A." London, CIBSE, 2015.

[22] https://www.ansys.com/search?keyword=Computational\%20Fluid\%20Dy namics\%20(CFD)

[23] https://passipedia.org/planning/calculating_energy_efficiency/phpp_the_p assive_house_planning_package\#phpp_passive_house_planning_package

[24] Arup, "Passive Design Assistant (PDA)" Version 1.0, W1T 4BQ, London, (2012). http://www.arup.com/

[25] Melissa Taylor, "Preventing Overheating", Good homes alliance, (2010) www.goodhomes.org.uk 